\title{
PARAMETERS INFLUENCING THE RESPONSE OF A BASE-ISOLATED BUILDING
}

\begin{abstract}
In order to illustrate the effect of damping on the response of a base-isolated building, a large investigation was undertaken. It consists of a parametric study, which takes into account the progressive variation of the damping ratio (10\% to 30\%) under different seismic excitations. Using a time history analysis of displacements and accelerations at various levels of the building, the results show that the efficiency of the isolator increases with the assumed damping ratio, provided that the latter is less than or equal to $20 \%$. Beyond this value, the isolator becomes less useful.
\end{abstract}

\section{INTRODUCTION}

In civil engineering, one of the main worries of researchers is to reduce the damage caused by earthquakes to structures. In this context, it has been proved that mounting structures on a base isolation is an important design strategy for protecting buildings from an earthquake's strong motions [7].

In this technique, a portion of the structure is isolated from the complete intensity of the seismic excitation, and a great quantity of energy is dissipated using specific artificial techniques [21].

A significant investigation in the development of new methods of seismic resistant design has been carried out in New Zealand, Skinner et al., 1975 [24]; 1976 [26]; 1982 [27]; 1984 [25], leading to the well-known "Laminated Rubber Bearing" (LRB). These new isolation concepts, featuring a cylindrical plug of lead in a central hole, were developed in the late 1970s, Robinson et al., 1977 [2223], as it was determined that the inherent damping in the rubber compounds available in Australia and New Zealand at that time was inadequate to control the displacements of the isolation system [14].

The main use of the lead central part is to reduce the lateral displacement and offer an additional mechanism for energy dissipation, whereas the rubber bearing increases the flexibility and restoring force [13].

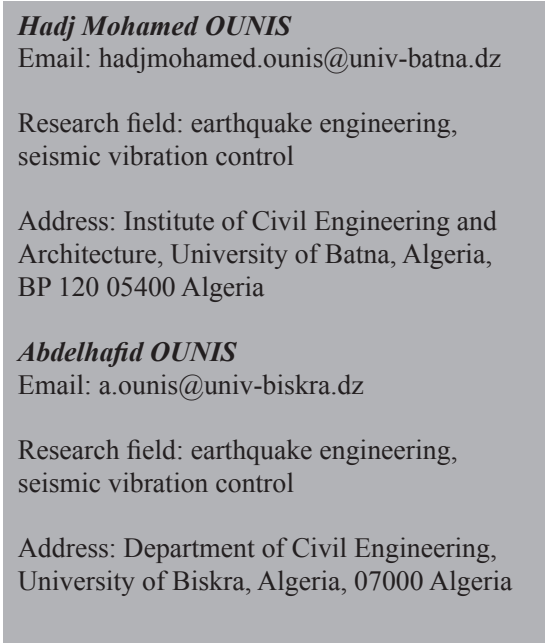

\section{KEY WORDS}

\section{- Damping,}

- base isolation,

- $L R B$,

- seismic excitation,

- hysteresis.
This fact reduces inertial forces and accelerations several times in a structure, but the additional flexibility due to the first natural period induces a large displacement at the isolation level. So, the latter must be reduced to a tolerable level by energy dissipation using external dampers or introducing damping in the bearing itself, which is necessary to maintain the isolator displacement inside acceptable limits in the case of low-frequency ground motion. Kelly, 1986 [14] and Buckle and Mayes, 1990 [6], carried out an extensive review of the historical developments of the many mechanisms that have been developed. While Bhasker, Rao and Jangid, 2001 [5] conducted an experimental and analytical study on a base-isolated structure having only one lateral degree of freedom with a lumped mass system, Tsai and Kelly, 1993 [29], extended this study to a greatly damped base-isolated shear building with a lumped mass system, which led to the result that increasing the isolation damping will enlarge the super-structure acceleration with a lumped mass system subjected to stationary random excitation, provided that the damping ratio of the isolation system remains beyond some level.

Seismic isolation for multistory buildings has been well evaluated and reviewed (Hong and Kim, 2004) [9]; (Barata and Corbi, 2004) [4]; (Agarwal, 2007) [1]; (Komodros, 2008) [15]; (Lu and Lin, 2008) [18]; (Spyrakos, 2009) [28]; (Panayiotis et al 2010); (Islam et al., $2011 \mathrm{a}$ and b) $[10,11]$. A base isolator with hardening be- 


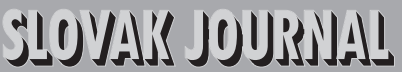 \\ 1) $5^{5}$

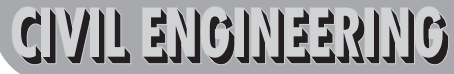

Vol. XXI, 2013, No. 3, $31-42$

havior under an increasing load has been developed for medium-rise buildings (up to four storeys) and sites with moderate earthquake risk (Pocanshi and Phocas, 2007) [20]. A nonlinear seismic response evaluation was performed by Balkaya and Kalkan (2003) [3]. The resonant behavior of a base-isolated high-rise building under long-duration ground motion was dealt with by Ariga et al. (2006) [2], and long-duration ground motion building responses by Olsen et al. (2008) [19]. Wilkinson and Hiley (2006) [31] presented a nonlinear response history model for the seismic analysis of high-rise framed buildings.

One could note that in most of the studies carried out, the behavior of the framed structure is modeled as a shear building with one degree of freedom attached to the center of the mass of each floor, but neglecting the effects of other degrees of freedom on the response.

However, Krishnamoorthy et al., 2009 [16] studied the response of a multistory framed structure resting on a nonlinear rubber bearing, which was analyzed by considering all the six degrees of freedom (translations and rotations) at each node, and subjected to the bi-directional harmonic excitation frequencies of the El Centro and Turkey earthquakes' excitations.

A nonlinear analysis of the different parameters affecting the response of a structure with LRB isolation has permitted the determination of the key parameters for an optimum conception of an LRB isolator. It consists of a very extensive parametric study which takes into account an incremental variation of the damping ratio. The optimal value of this variation has been searched for under different types of seismic records: near fault records, such as those of the Lexington, Sylmar and El Centro stations, and moderate excitation records, such as those of the Oak Wharf station.

Other parameters proved to be necessary to a realistic understanding of the isolator behavior, particularly the proportion of the predominant seismic excitation frequency to the natural frequency of the superstructure.

Thus, an extensive investigation shows the efficiency of the LRB system, mainly based on its capacity for energy absorption and dissipation according to the damping ratio.

\section{MODELING OF THE LRB SYSTEM}

LRB systems exploit the principle of the laminated bearing and its lateral flexibility. The LRB isolation system is similar to a laminated rubber bearing with a central hole into which the lead core is press-fitted as shown in Fig.1. The core of lead is used to provide additional energy dissipation, which significantly reduces lateral displacements. The system essentially becomes a damper hysteresis device. The force deformation characteristics of the hysteretic damper can be exactly modeled by a set of coupled non-linear differential equations. Typical hysteresis loops, such as elastic-plastic, rigid friction, bi-linear and smooth hysteretic, are generated by attributing appropriate values to the variables of the differential equation [13].

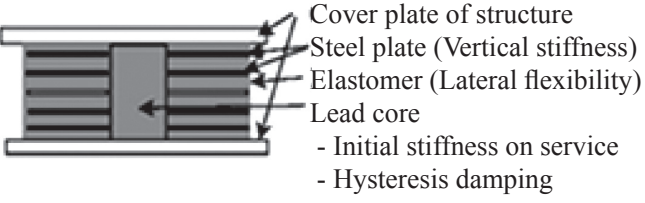

Fig. 1 Components of the LRB system.

The LRB system is shown in Fig. (2a); the schematic model is shown in Fig. (2b); and the force-deformation behavior is shown in Fig. (2c).

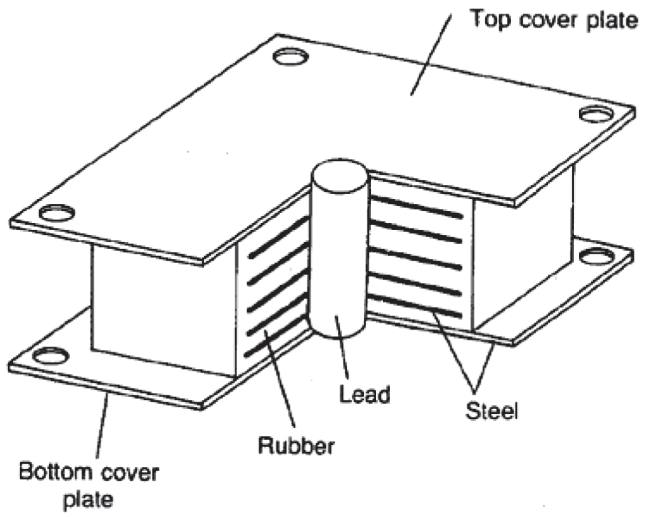

Fig. 2.a Lead rubber bearing.

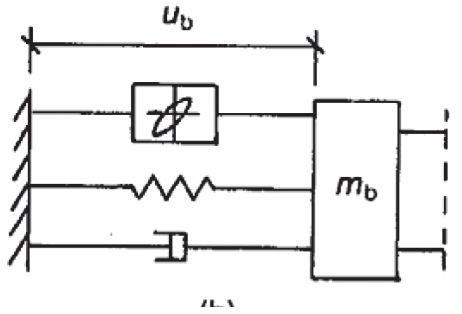

Fig. 2.b Mathematical model of the LRB system.

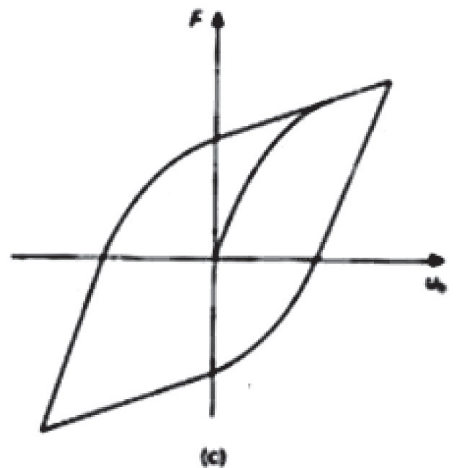

Fig. 2.c Hysteresis loop force-eformation for the LRB system. 


\section{MODELING OF A BASE-ISOLATED BUILDING}

For the present study, an idealized mathematical model of the $\mathrm{N}$ story structure is shown in Fig. 3(a). The base-isolated building is modeled as a shear-type structure mounted on isolation systems with two lateral degrees-of-freedom on each floor.

The following assumptions are made for the structural system under consideration:

1. During an earthquake excitation, the superstructure is considered to remain within the elastic limit. This assumption is valid in the presence of the isolator, which reduces the response of the structure considerably.

2. The floors are assumed to be rigid in their planes, and the mass is supposed to be lumped on each floor level.

3. The columns are inextensible and weightless and provide lateral stiffness.

4. The system is subjected to two horizontal components of the earthquake's ground motion.

5. The effects of any soil-structure interaction are not taken into consideration.

One lateral dynamic degree-of-freedom on each floor and the base mass is considered. Therefore the dynamic degrees-of-freedom are $\mathrm{N}+1$ for the $\mathrm{N}$-storey superstructure.

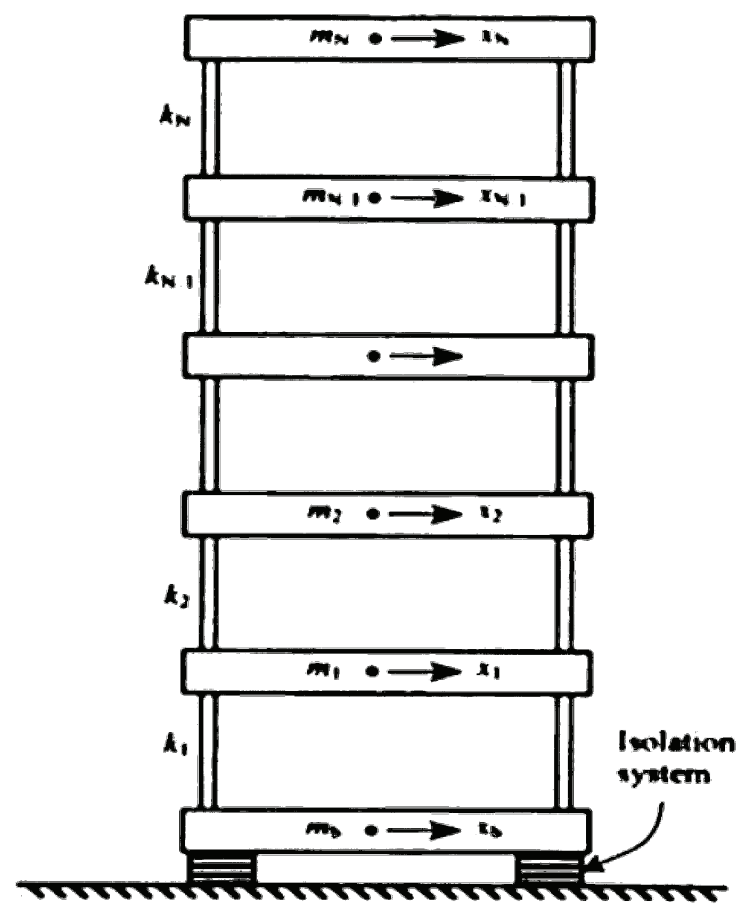

Fig. 3.a Mathematical model of the $N$-story base-isolated building.
The governing equations of motion for the fixed-base $\mathrm{N}$-story superstructure model are expressed in a matrix form as:

$$
[\mathrm{M}]\{\ddot{\mathrm{x}}\}+[\mathrm{C}]\{\dot{\mathrm{x}}\}+[\mathrm{K}]\{\mathrm{x}\}=-[\mathrm{M}]\{1\}\left(\ddot{\mathrm{x}}_{\mathrm{b}}+\ddot{\mathrm{x}}_{\mathrm{g}}\right)
$$

where $[\mathrm{M}],[\mathrm{C}],[\mathrm{K}]$ are, respectively, the mass, damping, and stiffness matrices of the fixed base of the order $\mathrm{N} \mathrm{x} \mathrm{N}$.

$\{\mathrm{x}\}=\left\{\mathrm{x}_{1}, \mathrm{x}_{2}, \mathrm{x}_{3} \ldots \mathrm{x}_{\mathrm{n}}\right\}^{\mathrm{T}}$, is the displacement of the superstructure; $x_{j}=(j=1,2,3 \ldots N)$, is the lateral displacement of the $j$ th floor relative to the base mass; $\{1\}=\{1,1,1 \ldots 1\}^{\mathrm{T}}$ is the influence coefficient vector; $\{\mathrm{x}\},\{\dot{\mathrm{x}}\}$, and $\{\ddot{\mathrm{x}}\}$, are the unknown relative floor displacements, velocity, and acceleration vectors, respectively.

$\ddot{x}_{\mathrm{b}}$, and $\ddot{\mathrm{x}}_{\mathrm{g}}$ are the relative accelerations of the base mass and the earthquake's ground acceleration, respectively.

The structural model of the isolated building is represented in Fig. 3(a) as follows:

Fig. 3(b) shows the Bilinear Hysteretic model for the LRB isolator.

The corresponding equation of motion for the base mass under an earthquake's ground acceleration is expressed by

$$
\mathrm{m}_{\mathrm{b}} \ddot{\mathrm{x}}_{\mathrm{b}}+\mathrm{c}_{\mathrm{b}} \dot{\mathrm{x}}_{\mathrm{b}}+\mathrm{F}_{\mathrm{b}}-\mathrm{k}_{1} \mathrm{x}_{1}-\mathrm{c}_{1} \dot{\mathrm{x}}_{1}=-\mathrm{m}_{\mathrm{b}} \ddot{\mathrm{x}}_{\mathrm{g}}
$$

where

$\mathrm{m}_{\mathrm{b}}$ is the mass of the base raft;

$\mathrm{F}_{\mathrm{b}}$ is the restoring force developed in the LRB isolation system,

$\mathrm{k}_{1}$ is the stiffness of the first floor of the superstructure;

$c_{1}$ is the damping of the first story of the superstructure.

The restoring force developed in the isolation system $\mathrm{Fb}$ depends upon the type of isolation system considered and on the approximate numerical models used.

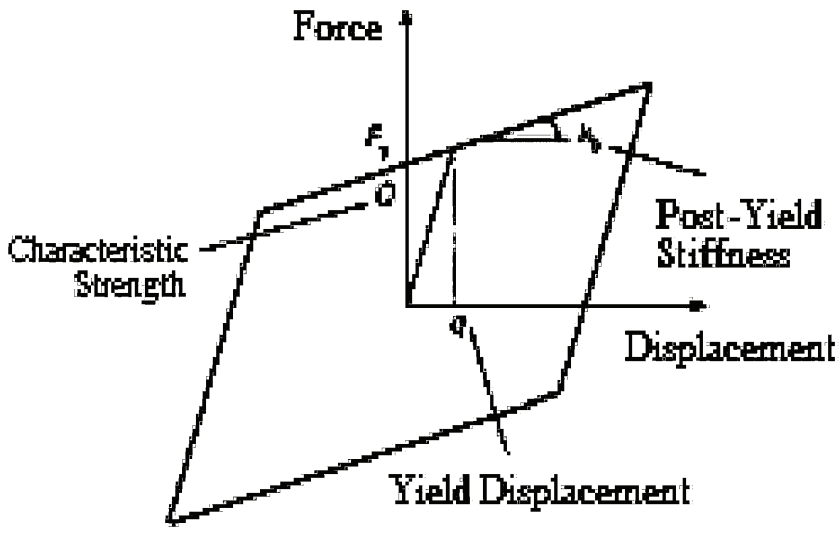

Fig. 3.b Bilinear Hysteretic model for the LRB isolator. 


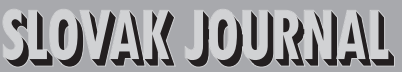 \\ 1) 5

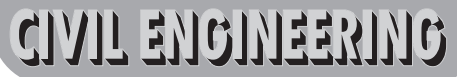

Vol. XXI, 2013, No. 3, $31-42$

\section{MATHEMATICAL MODEL OF THE LRB SYSTEM}

For the present study, the force-deformation behavior of the isolator is modeled as nonlinear hysteretic and represented by a bilinear model, Vasant, 2004 [30]

The nonlinear force-deformation behavior of the isolation system is modeled through the bilinear hysteresis loop characterized by three parameters, namely, (i) characteristic strength, Q, (ii) postyield stiffness, $k_{b}$, and (iii) yield displacement, $q$ ( see Fig. 3(b). The bilinear behavior is selected, because this model can be used for all isolation systems found in practice. The characteristic strength $Q$ is related to the yield strength of the lead core in the elastomeric bearings and the friction coefficient of the sliding type isolation system; $\mathrm{k}_{\mathrm{b}}$ is generally designed in such a way as to provide the specific value of the isolation period $T_{b}$, expressed as

$$
\mathrm{T}_{\mathrm{b}}=2 \pi \sqrt{\frac{\mathrm{M}}{\mathrm{k}_{\mathrm{b}}}}
$$

Where $\mathrm{M}=\left(\mathrm{m}_{\mathrm{b}}+\sum_{\mathrm{j}=1}^{\mathrm{N}} \mathrm{m}_{\mathrm{j}}\right)$ is the total mass of the base-isolated structure of the jth floor of the superstructure.

The yield strength of the bearing is normalized with respect to the total weight of the isolated building and expressed by the parameter $\mathrm{F}_{0}$, defined as:

$$
\mathrm{F}_{0}=\frac{\mathrm{F}_{\mathrm{y}}}{\mathrm{W}}
$$

Where $\mathrm{W}=\mathrm{M} \cdot \mathrm{g}$ is the total weight of the isolated building, and $\mathrm{g}$ is the acceleration due to gravity.

The viscous damping $\mathrm{c}_{\mathrm{b}}$ in the bearing due to the rubber is evaluated by the damping ratio, expressed as:

$$
\xi_{\mathrm{b}}=\frac{\mathrm{c}_{\mathrm{b}}}{2 \mathrm{~m} \omega_{\mathrm{b}}}
$$

Where $\omega_{\mathrm{b}}=2 \pi / \mathrm{T}_{\mathrm{b}}$ is the base isolation frequency.

Thus, the modeling of LRB requires the specification of four parameters, namely, the isolation period $\left(\mathrm{T}_{\mathrm{b}}\right)$, damping ratio $\xi_{\mathrm{b}}$ ), normalized yield strength $\mathrm{F}_{0}$ and yield displacement $(\mathrm{q})$.

\section{SOLUTION OF MOTION EQUATIONS}

In this situation the Classical Model Superposition technique cannot be employed in the solution of equations of motion here because

1 The system is non-classically damped because of the difference in damping in the isolation system and in the superstructure.

2 The force-deformation behavior in the isolation systems considered is non-linear.
Therefore, the equations of motion are solved numerically using Newmark's method of step-by-step integration, i.e., adopting a linear variation of acceleration over a small time interval of $\Delta t$. The time interval for solving the equations of motion is taken as $0.02 / 200$ s (i.e., $\Delta \mathrm{t}=0.0001 \mathrm{~s})$.

\section{PARAMETRIC STUDY}

To illustrate the effect of damping on the response of a building with base isolation, an extensive investigation was undertaken. A reinforced-concrete building of ten stories regular in plan and with an elevation of $15 \times 20 \mathrm{~m}$ is considered with four bays in a longitudinal direction and three bays in a transverse direction placed $5 \mathrm{~m}$ apart. The sections of the beams are $30 \times 45 \mathrm{~cm}^{2}$; the sections of the columns are $50 \times 50 \mathrm{~cm}^{2}$; and the floor height is $3 \mathrm{~m}$ with solid slabs $20 \mathrm{~cm}$ thick.

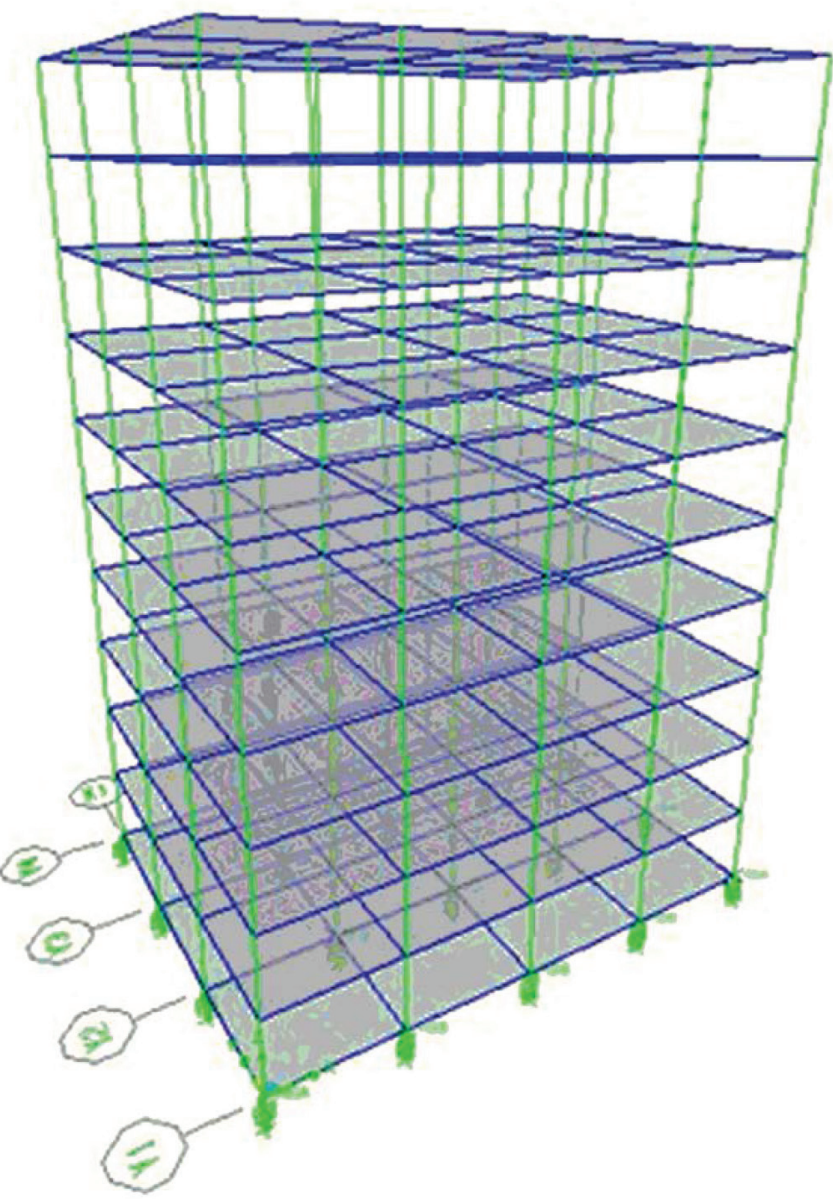

Fig. 4.a $3 D$ view of the isolated structure. 


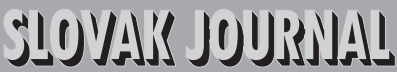

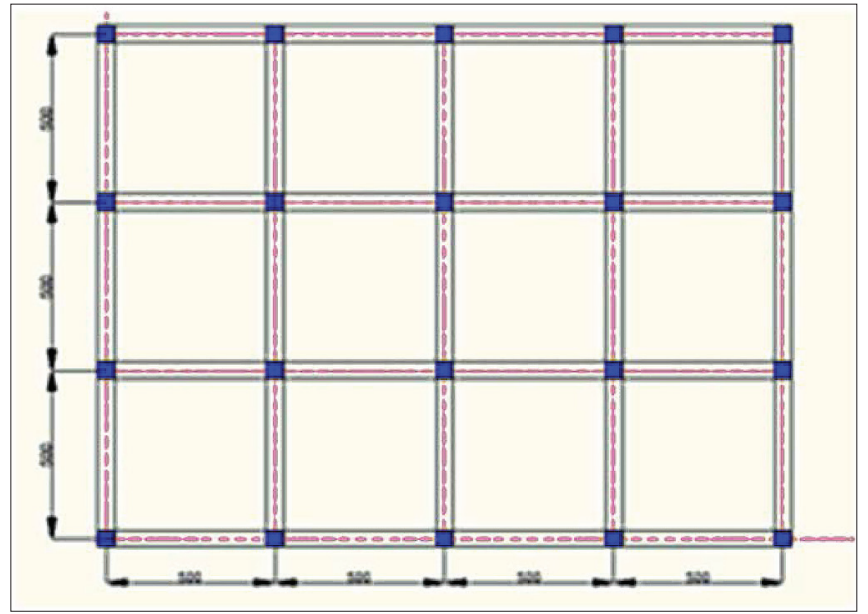

Fig. 4.b Plan view of the isolated structure.

- The seismic excitations considered in this study are:

- The component of the El Centro Imperial Valley earthquake (1979),

- The component of the Outer Harbor Wharf in the Oakland Loma Prieta earthquake (1989),

- The component of the Lexington Dam Loma Prieta earthquake (1989),

- The component of the Sylmar County Northridge earthquake (1994), with Peak Ground Accelerations (PGA) of $0,436 \mathrm{~g}, 0,287 \mathrm{~g}, 0,442 \mathrm{~g}$ and $0,604 \mathrm{~g}$, respectively.

The frequency analysis of these accelerograms showed that the frequency ranges of the seismic excitations are distributed as follows:

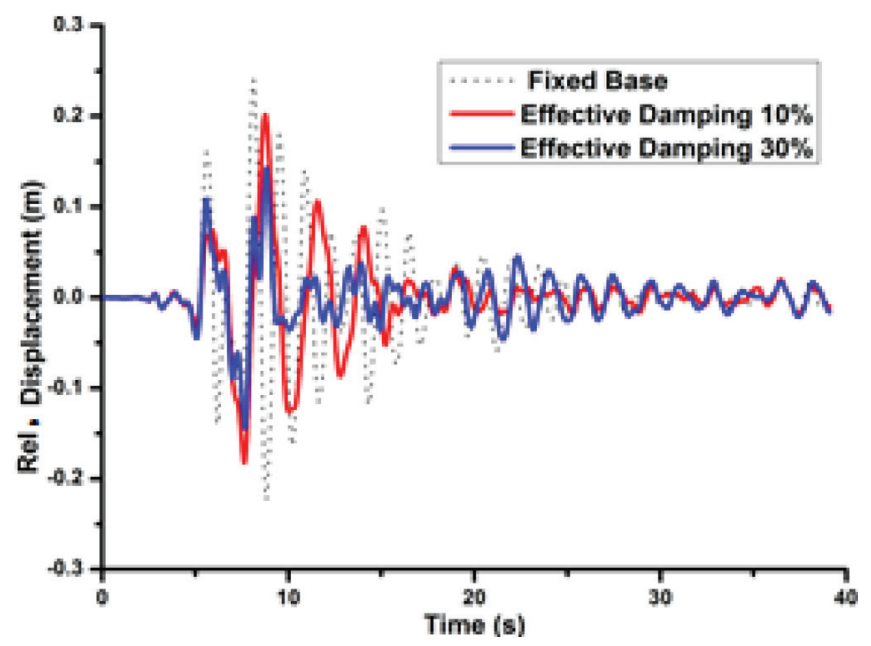

Fig. 5 Comparison of the relative displacement of the top level between the fixed base and the isolated base with low (10\%) and high (30\%) effective damping ratios subjected to the component of the El Centro Imperial Valley Earthquake.
- The component of the El Centro Imperial Valley: 0.15 to $0.5 \mathrm{~Hz}$.

- The component of the Outer Harbor Wharf in Oakland Loma Prieta: 0.5 to $1.65 \mathrm{~Hz}$.

- The component of the Lexington Dam Loma Prieta: 0.65 to $2.45 \mathrm{~Hz}$.

- The component of the Northridge Sylmar County: 0.35 to $3.6 \mathrm{~Hz}$.

The numerical simulation was run using ETABS V9.7.2 software, which is produced by the firm of Computers and Structures, University of Berkeley, CA, USA.

\section{RESULTS}

\subsection{Relative displacement}

The curves in Fig. 5 resulting from the excitation of El Centro for a conventional building and a base isolated building of the LRB type, show a reduction in the relative displacement of the floor of (16.05 and $39.98 \%)$ for a damping ratio of (10\% and 30\%) respectively. Thus, the energy dissipation seems less promising specifically for this excitation, on the one hand, and there is a strong proportionality between the reduction of the displacement and the damping ratio on the other hand.

From these curves obtained by the Lexington component, we deduce that there is a strong energy dissipation by the isolation system, which resulted in the reduction of the relative displacement of the floor with a very high ratio (64.91 and $65.25 \%$ ) for a damping ratio of (10 and $30 \%$, respectively). We also observe that the increase in the damping ratio is insignificant for this type of excitation as the reduction of the displacement is nearly constant.

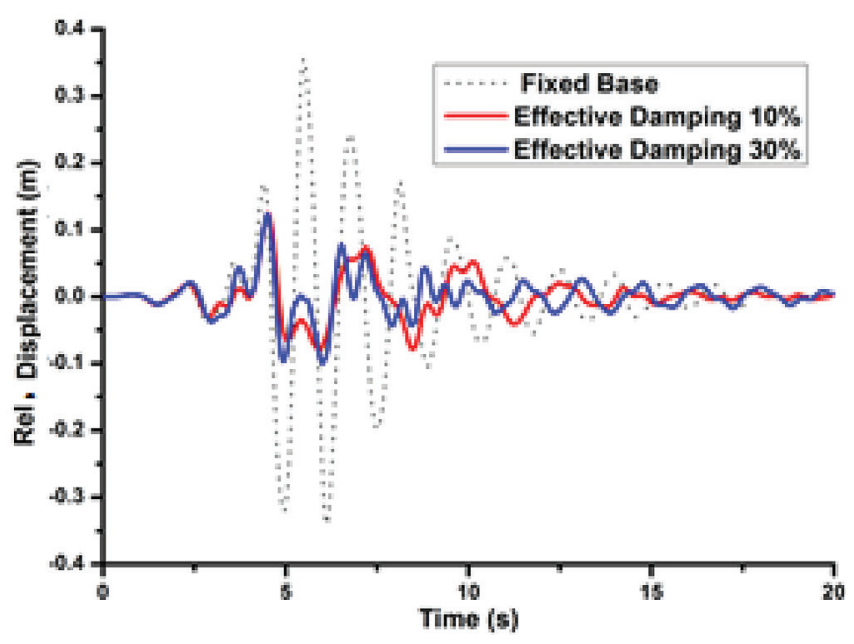

Fig. 6 Comparison of the relative displacement of the top level between the fixed base and the isolated base with low (10\%) and high (30\%) effective damping ratios subjected to the component of the Lexington Dam Loma Prieta earthquake. 


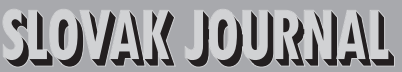 \\ 1) $\vec{s}$

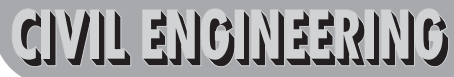

Vol. XXI, 2013, No. 3, $31-42$

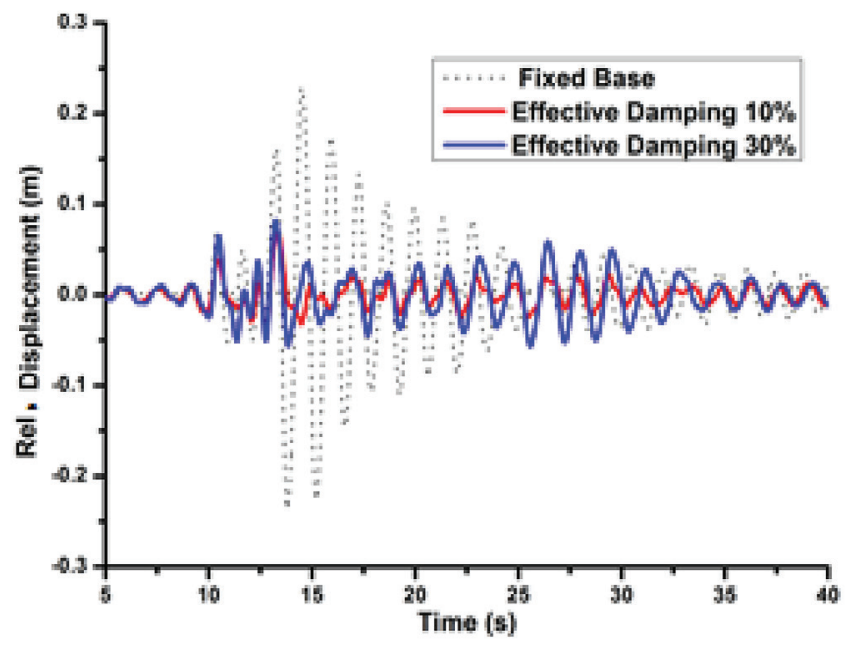

Fig. 7 Comparison of the relative displacement of the top level between the fixed base and the isolated base with low (10\%) and high (30\%) effective damping ratios subjected to the component of the Oakland Outer Loma Prieta Earthquake.

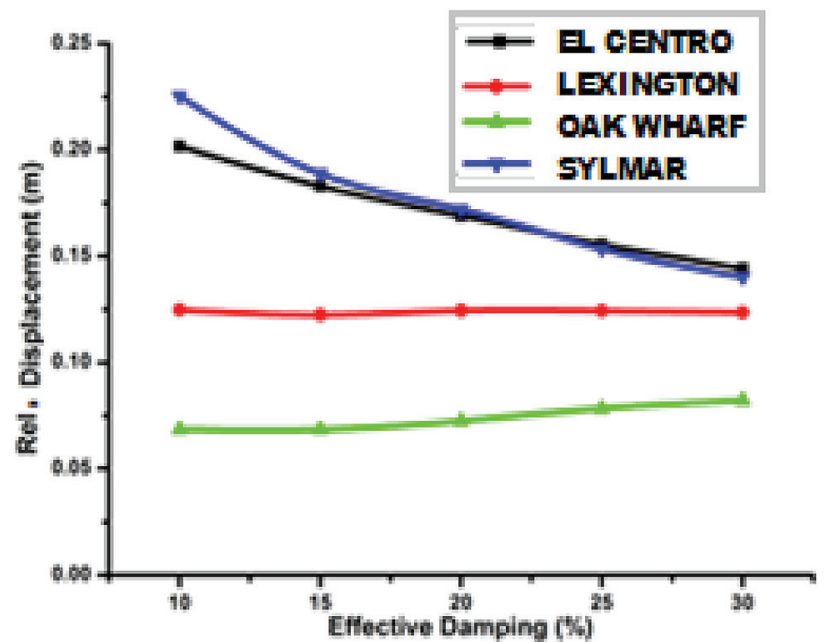

Fig. 9 Maximum Relative Displacement of the top level with different effective damping ratios subjected to a multitude of seismic excitations.

Under the effect of the component of the Oakland Outer Loma Prieta Earthquake, there was a deviation of almost all of the seismic energy to the LRB isolator, which resulted in a strong reduction of the relative displacement estimated at the top (70.03 and $64.10 \%)$ under damping ratios of (10 and 30\%), respectively, which makes the isolation system highly efficient.

The graph in Fig. 8 shows that higher levels of the damping ratio of the isolator result in a highly significant reduction in the relative

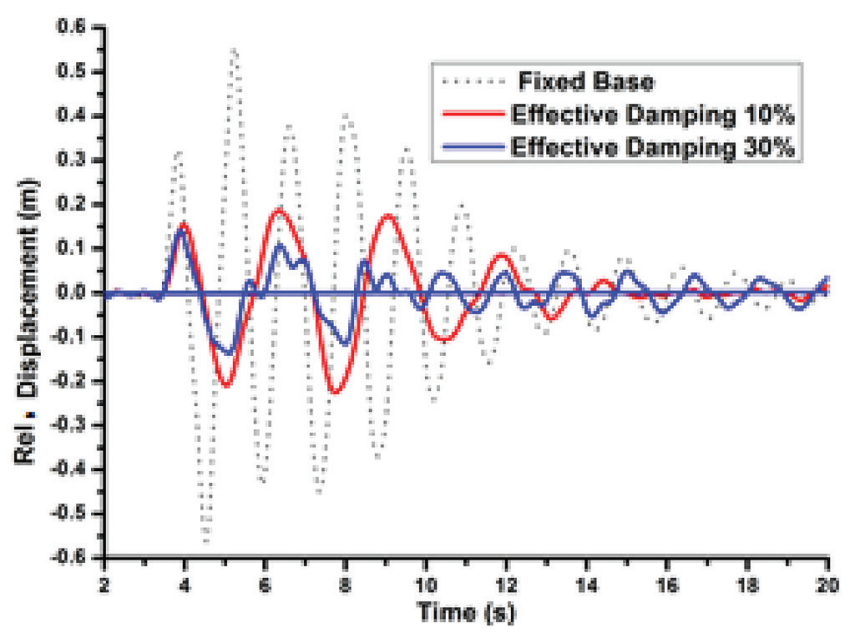

Fig. 8 Comparison of the relative displacement of the top level between the fixed base and the isolated base with low (10\%) and high (30\%) effective damping ratios subjected to the component of the Sylmar County Northridge earthquake.

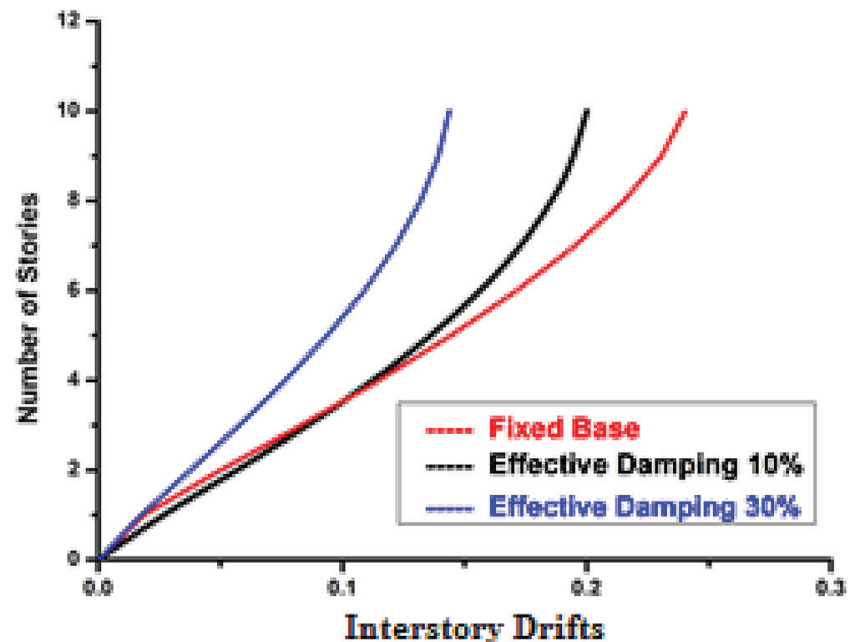

Fig. 10 Comparison of the interstory drifts between the fixed base and the isolated base with low (10\%) and high (30\%) effective damping ratios subjected to the component of the El Centro Imperial Valley Earthquake.

displacement, which implies that the base isolation is very effective for this excitation. The reduction of the relative displacement is estimated at (59.39 and $74.70 \%$ ) for a damping ratio (10 and 30\%), respectively.

The graph shows the variation of the relative displacement Top Max as a function of the variation in the damping ratio for different seismic excitations, which therefore suggests that the LRB isolation system is effective because of the high reduction in the ratio of relative displacements, which may exceed $74 \%$ with certain types of 


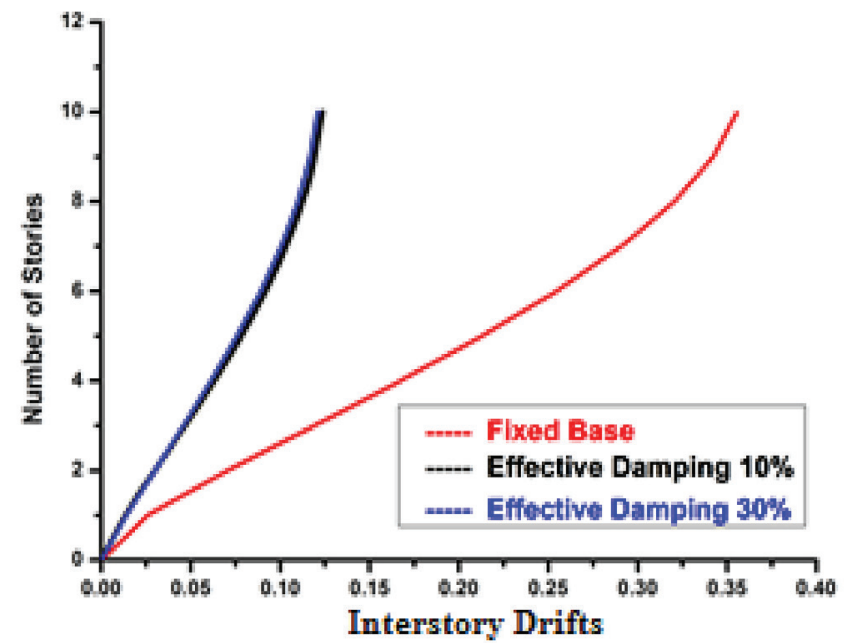

Fig. 11 Comparison of the interstory drifts between the fixed base and the isolated base with low (10\%) and high (30\%) effective damping ratios subjected to the component of the Lexington Dam Loma Prieta earthquake.

excitations. We observe for the Sylmar and El Centro excitations that the damping ratio is proportional to the top relative displacements, which can reach $0.14 \mathrm{~m}$. However for the Oak Wharf and Lexington excitations, there is almost a complete stagnation in the reduction of the top relative displacement; therefore, increasing the damping ratio of the isolator is not necessary. In conclusion, the LRB isolator is more effective for the Oak Wharf excitation as reflected by a significant reduction in the top relative displacement.

\subsection{Interstory Drifts}

The curves in Fig. 10 result from a comparative study of the interstory drift in a conventional building equipped with a LRB isolation base with damping ratios of 10 and $30 \%$. For the El Centro excitation, we recorded reductions of 16.79 and $40.16 \%$ in the interstory floor-terrace displacements for the damping ratios of 10 and $30 \%$, respectively. Thus, while smaller reductions were observed for the damping ratios of $10 \%$, substantial reductions were observed for the high damping rates $(30 \%)$.

For the excitation of the Lexington Dam, the interstory drifts are estimated at 65.25 and $66.03 \%$ for damping ratios of 10 and $30 \%$, respectively. Thus, on the one hand, we can observe a strong reduction in the interstory drifts reaching up to a level of $66 \%$, which reflects the reliability of the LRB isolation system. On the other hand, we observe that the two curves corresponding to the damping ratios of 10 and $30 \%$ are close to each other; thus, for technical and economic considerations, we limit ourselves to the LRB excitation system with a $10 \%$ ratio.

The results under the Oak Wharf excitation are practically the same as that of the Lexington excitation. They are characterized by

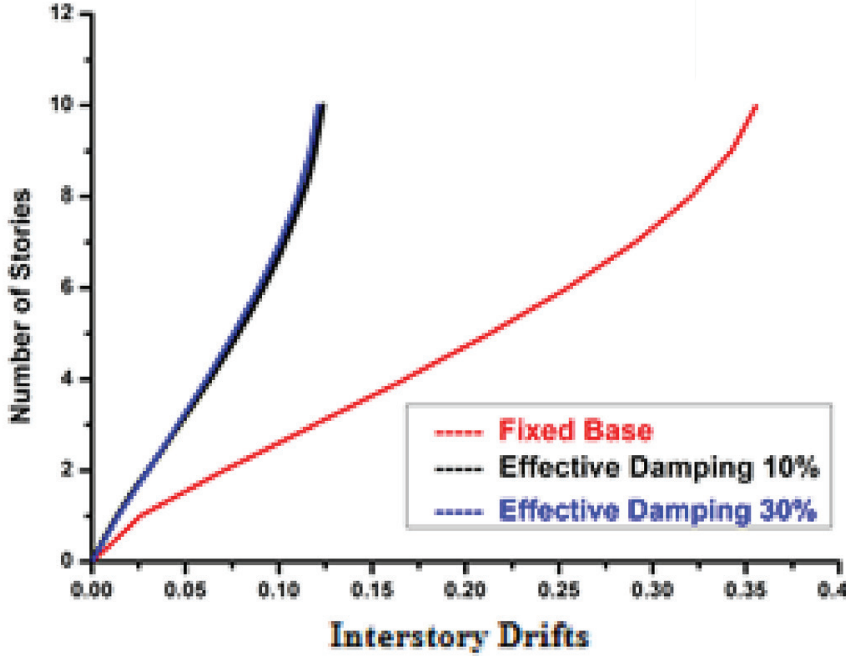

Fig. 12 Comparison of the interstory drifts between the fixed base and the isolated base with low (10\%) and high (30\%) effective damping ratios subjected to the component of the Oakland Outer Loma Prieta Earthquake.

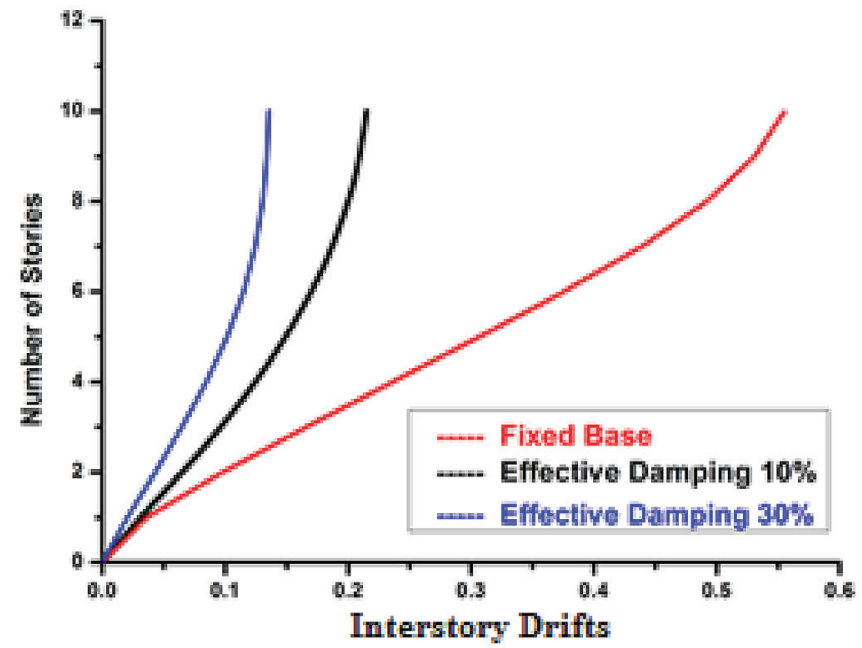

Fig. 13 Comparison of interstory drifts between the fixed base and the isolated base with low (10\%) and high (30\%) effective damping ratios subjected to the component of the Sylmar County Northridge earthquake.

a significant reduction in the interstory drift, estimated at 71.43 and $70.23 \%$ for damping ratios of 10 and $30 \%$, respectively. Therefore, the LRB isolation system with a $10 \%$ damping ratio is adequate in reducing the interstory drift with an estimated reduction of $71.43 \%$ (0.0682 m).

Despite an excitation characterized by a high Peak Ground Acceleration (PGA) $(0.604 \mathrm{~g}$ ) of that of Sylmar County, the interstory drifts are reduced proportionally to the damping ratio of the isolator. 


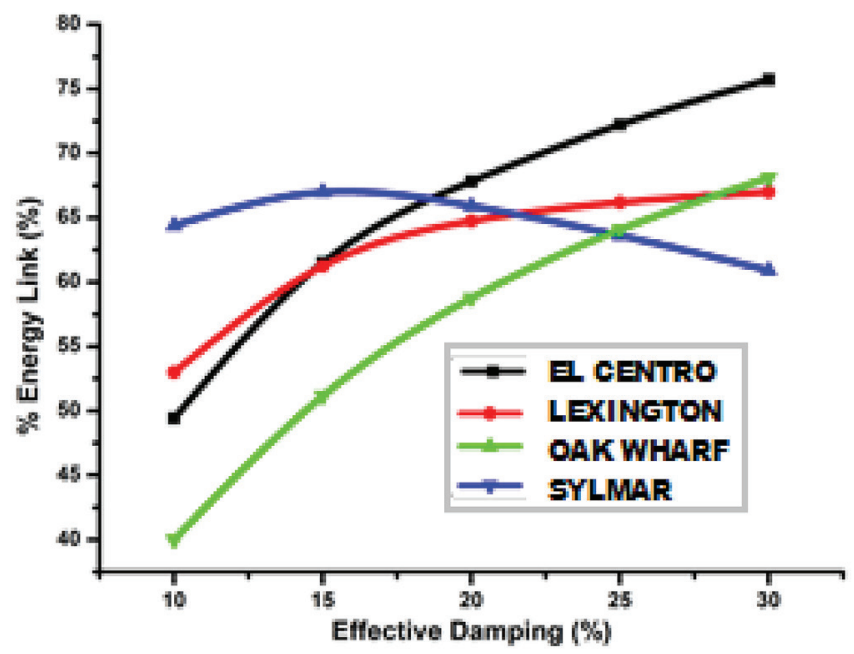

Fig. 14 Maximum of the \% Link Energy with different effective damping ratios subjected to a multitude of seismic excitations.

The reduction in displacements is estimated at 61.28 and $75.57 \%$ for damping ratios of 10 and $30 \%$, respectively. Therefore, the LRB isolation system is very effective in reducing the interstory drift with reductions reaching up to $75 \%$ with a value of $0.1358 \mathrm{~m}$.

\subsection{Energy balance}

When a structure is subjected to a strong earthquake, the system energy of the structure can be expressed as follows:

$$
\mathrm{IE}=\mathrm{KE}+\mathrm{PE}+\mathrm{LE}+\mathrm{MDE}
$$

where

$\mathrm{IE}=$ Input Energy,

$\mathrm{KE}=$ Kinetic Energy,

$\mathrm{PE}=$ Potential Energy,

$\mathrm{LE}=$ Link Element Energy,

$\mathrm{MDE}=$ Modal Damping Energy.

The curves in Fig. 14 represent the maximum percentage of the link energy absorbed by the isolator according to its damping ratio under different seismic excitations with different natural (near and far fields), and different frequency contents. Each curve corresponds to the analysis of a single excitation:

- For the El Centro excitation, we observed that the energy absorbed by the isolator is proportional to the damping ratio, but this variation is not perfectly linear. We also recorded dissipation ratios of 49.43 and $75.73 \%$ for the damping ratios of 10 and $30 \%$, respectively. Therefore, the optimal value (technical-economic) can be achieved at a ratio of $20 \%$ (corresponding to $67.82 \%$ of the Input Energy absorbed by the LRB isolation system),

- According to the LEXINGTON accelerogram, we observed, at a $10 \%$ damping ratio, a slight increase in the dissipation of

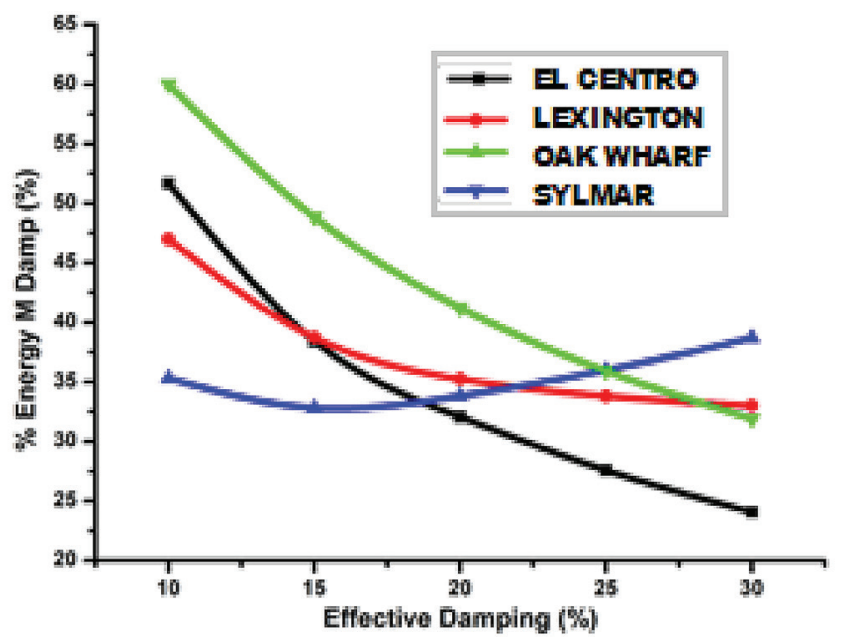

Fig. 15 Maximum of the \% M Damping Energy with different effective damping ratios subjected to a multitude of seismic excitations.

the input energy equal to $52.99 \%$ as compared to that of the EL CENTRO. One can subdivide the curve into two parts: the first part is roughly increasing (between $10 \%$ and $20 \%$ ), while the second part is slightly monotonous. Therefore, the most appropriate damping ratio is $20 \%$ (corresponding to $64.75 \%$ of the Input Energy absorbed by the LRB, which is slightly lower than that of EL CENTRO).

- According to the curve for the OAKWHARF excitation, the percentage of damping is inversely proportional to the dissipation of the Input Energy; specifically, the dissipation decreases according to a curvilinear trend as the damping ratio increases. It is interesting to note that a strong dissipation of the Input Energy is recorded (64.39\%) for a damping ratio of $10 \%$, which is equivalent to the dissipations under EL CENTRO and is even closer to that of the LEXINGTON ratio of $20 \%$. Therefore, we opt for an isolation system with a damping ratio of $10 \%$ for this excitation.

- Based on the SYLMAR accelerogram, we observe that the dissipation by the isolator is similar to that of EL CENTRO, but with a lag almost uniformly estimated at $9 \%$. The optimal value of the damping ratio is estimated at $20 \%$, which corresponds to an estimated dissipation of the Input Energy of $58.77 \%$.

The curves in Fig. 15 show the variations in the energy from the modal damping of the superstructure based on the damping ratio of the isolator under diverse seismic excitations of different natures. We mainly observe that the evolution of energy from the modal damping of the structure is determined symmetrically from the link energy absorbed by the isolator. In other words, the two types of energy are inversely proportional, i.e., complementary. 


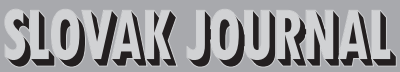 \\ 1) 5

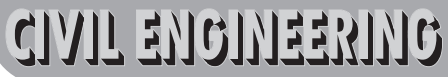

Vol. XXI, 2013, No. 3, $31-42$

7.4 Energy absorbed by the LRB system
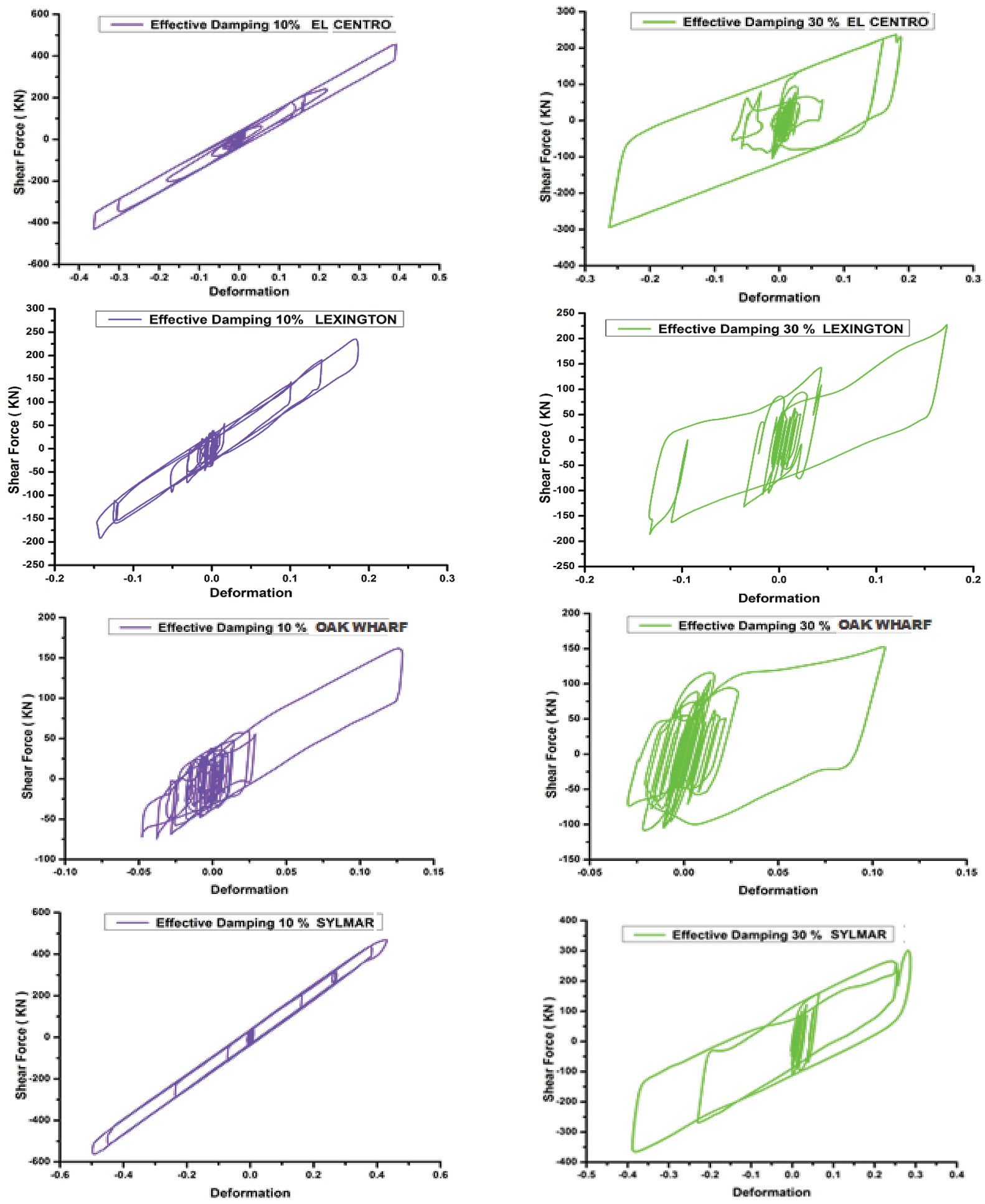

Fig. 16 Force-Deformation Hysteresis Loop. 
Fig. 16 includes a set of hysteresis curves that describe the energy absorption capacity of the isolator at damping rates of 10 and $30 \%$ under four different types of excitations. We observe from the curves below that the higher damping rates correspond to an increase in the surface of the hysteresis curve. This suggests the effectiveness of using the LRB system as reflected by the high absorption capacity of the seismic energy input.

\section{CONCLUSION}

This investigation concerns the comparison of a conventional building to a building with an LRB-based isolation through a very broad parametric study. It aims to find the optimal characteristics of the LRB isolation system, subjected to different seismic excitations of different natures and different levels of damping rates of the LRB isolators (10 to $30 \%$ ). This simulation yielded the following results:

- The relative displacement of a floor to terrace is greatly reduced, at a rate of approximately $65 \%$ for all the excitations except for that of the El Centro. Therefore, the LRB system is most appropriate at a damping rate of $20 \%$.

- We observe that the interstory displacement mainly depends on the nature of the seismic excitation. The average displacement reduction is estimated at $40 \%$ for the high damping rates under the El Centro excitation; in contrast, there is a strong reduction of the interstory displacement (65 and 70\%) at a low damping rate $(10 \%)$ under the Lexington and Oak Wharf excitations, respectively. Moreover, we record for these two excitations a perfect coincidence of the two curves at different damping rates (10 and 30\%). A high attenuation (estimated at $61 \%$ ) was observed for the Sylmar excitation, even at a low rate of depreciation $(10 \%)$, although this excitation is characterized by a high PGA $(0.604 \mathrm{~g})$. Therefore, the LRB isolator with a low damping rate $(10 \%)$ reduces the interstory displacement, on average by $65 \%$.

- The LRB isolator plays the major role for which it has been designed. This results, on the one hand, in an increase in the surface of the hysteresis curve, and, on the other hand, in a high energy absorption estimated at an average rate of $65 \%$ for an optimum damping rate of $20 \%$. This indicates the major effect of the LRB isolator as an energy absorber.

- The protection provided by base isolation depends on the fundamental frequency of the structure and the frequency domain of the seismic excitation. Therefore, the structural type of the building and the soil conditions of the site can affect the efficiency of the isolation system.

- The optimal design of a system-based LRB isolation is controlled according to the ratio of the predominant frequency of the soil $(\mathrm{wg})$ and the fundamental frequency of the superstructure (ws), knowing that for small values of the ratio $\frac{\mathrm{w}_{\mathrm{g}}}{\mathrm{w}_{\mathrm{s}}}$, the system becomes less effective, which is the case of a flexible superstructure. In contrast, the LRB isolation system is more efficient when the ratio is close to unified.

- We note that the displacement at the base decreases when the ratio $\frac{\mathrm{w}_{\mathrm{g}}}{\mathrm{w}_{\mathrm{s}}}$ is increased; this means that the LRB isolator at the base is more suitable for structures with a rigid foundation. 


\section{REFERENCES}

[1] Agarwal, V.K. - Niedzwecki, J.M. - Van de Lindt, J.W. (2007) Earthquake induced pounding in friction varying base isolated buildings. Engineering Structures, 29, pp. 2825-2832.

[2] Ariga, - Kanno, Y.- Takewaki, I. (2006) Resonant behaviour of base isolated high-rise buildings under long-period ground motions. Struct. Des. Tall Special Build., 15, pp. 325-338.

[3] Balkaya, C. - Kalkan, E (2003) Nonlinear seismic response evaluation of tunnel form building structures. Computers \& Structures, 81, pp. 153-165.

[4] Baratta, A. - Corbi, I. (2004) Optimal design of base-isolators in multistorey buildings. Computers \& Structures, 82, 2004 , pp. 2199-2209.

[5] Bhasker, R. - Jangid, RS. (2001) Experimental study of Base isolated Structures. Journal of Earthquake Technology, 38,1, 2001, pp.1-15.

[6] Buckle, IG. - Mayes, RL. (1990) Seismic isolation: history, application and performance $-A$ world overview. Earthquake Spectra, 6, 2, 1990, pp. 161-201.

[7] Chung, L.L. - Yang, C.Y. - Chen, H.M. - Lu, L.Y. (2009) Dynamic behavior of nonlinear rolling isolation system. Structural Control Health Monitoring,; 16, 1, 2009, pp. 32-54.

[8] Constantinou, M.C. - Tadjbakhsh, I.G, (1985) Hysteretic dampers in base isolation: Random approach. American Society for Civil Engineering, 111, 4, 1985, pp. 705-721.

[9] Hong, W.- Kim, H. (2004) Performance of a multi-storey structure with a resilient-friction base isolation system. Computers \& Structures, 82, 27, 2004, pp. 2271-2283.

[10] Islam, ABMS. - Jameel, M. - Jumaat, M.Z. (2011a) Seismic isolation in buildings to be a practical reality: Behaviour of structure and installation technique. J. Eng. Technol. Res., Corrected Proof. 3, 4, 2011, pp. 97-117.

[11] Islam, ABMS. - Jameel, M. - Jumaat, M.Z. (2011b) Study on corollary of seismic base isolation system on buildings with soft story. Int. J. Phys. Sci., Press.

[12] Jangid, R.S. - Datta, T.K. (1995) Seismic behavior of base isolated buildings: a state of the art review. Civil Engineering Structures \& Buildings , 110, 2, May 1995, pp. 186-203.

[13] Kang, B.S. - Kang, G.J. - Moon, B.Y. (2003) Hole and lead plug effect on fiber reinforced elastomeric isolator for seismic isolation. Journal of Material Processing Technology 140, 1 , 2003, pp. 592-597.
[14] Kelly, J.M. (1986) Seismic base isolation: review and bibliography. Soil Dynamics Earthquake Engineering, 5, 4, 1986, pp. 202-216.

[15] Komodromos, P. (2008) Simulation of the earthquake-induced pounding of seismically isolated buildings. Computers \& Structures, 86, 2008, pp. 618-626.

[16] Krishnamoorthy - Kiran, K. Shetty (2009) Effect of isolation damping on the response of base isolated structure. Asian Journal of Civil Engineering (Building and Housing) 10, 6, 2009, pp. 701-716.

[17] Lee, D.M. - Medlan, I.C. (1979) Base isolation systems for earthquake protection of multistorey shear structure. Earthquake Engineering and Structural Dynamics,7, 6, 1979, pp. $555-568$.

[18] Lu, L.Y.,- Lin, G.L. (2008) Predictive control of smart isolation system for precision equipment subjected to near-fault earthquakes. Engineering Structures, 30,11, 2008, pp. 3045-3064.

[19] Olsen, A. - Aagaard, B. - Heaton, T. (2008) Long-period building response to earthquakes in the San Francisco Bay Area. Bull. Seismol. Soc. Am., 98: 1047

[20] Pocanschi, A. - Phocas, M.C. (2007) Earthquake isolator with progressive nonlinear deformability. Engineering Structures., 29, 10, 2007, pp. 2586-2592.

[21] Priestley, M.J.N. - Calvy, G.M. (1996) Seismic design and retrofit of bridges. Wiley International Publication, 458 pp.

[22] Robinson, W.H.- Tucker A.G. (1977) A lead-rubber shear damper. Bull. No. 2. Natl. Soc. Earthquake Eng., 10, 1977, pp. 151-153.

[23] Robinson, W.H. - Tucker, A.G. Test results for lead-rubber bearings for the Wm. Clayton Building, Toe Toe Bridge and Waiotukupuna Bridges. Bull. N. Z. Natl. SOC. Earthquake Eng. (in Press).

[24] Skinner, R.I. - Beck, J.L. - Bycroft, G.N. (1975) A practical system for isolating structures from earthquake attack. International Journal of Earthquake Engineering and Structural Dynamics, 3, 3, 1979, pp. 297-309

[25] Skinner, R.I. (1984) Base isolated structures in New Zealand. 8th World Conference on Earthquake Engineering, San Francisco, Vol. 5,1984, pp. 927-934.134

[26] Skinner, R.I. - Bycroft, G.N. - McVerry, G.H. (1976) Practical system for isolating nuclear power plants from earthquake attack. Journal of Nuclear Engineering and Design, Vol. 36, 1976, pp. 287-297. 


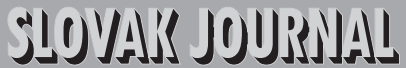 \\ 1)

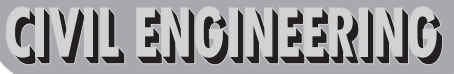

Vol. XXI, 2013, No. 3, $31-42$

[27] Skinner, R.I. (1982) Base isolation provides a large building with increased earthquake resistance: Development, design and construction. Proceeding of the International Conference on Natural Rubber for Earthquake Protection of Buildings and Vibration Isolation, Kuala Lumpur, Malaysia, Edited by Derham, C.J., pp. 82-102.

[28] Spyrakos, C.C. - Koutromanos, I.A. - Maniatakis, C.A. (2009) Seismic response of base-isolated buildings including soil-structure interaction. Soil Dyn. Earthquake Eng., 29,4, 2009, pp. 658-668.
[29] Tsai, H.C. - Kelly, JM. (1993) Seismic response of heavily damped base isolation. Journal of Earthquake Engineering and Structural Dynamics, 22, 7, 1993, pp. 633-645.

[30] Vasant, A.M. - Jangid, R.S. (2004) Influence of isolator characteristics on the response of base-isolated structures. Engineering Structures, 26, 12, October 2004, pp. 1735-1749.

[31] Wilkinson, S. - Hiley, R. (2006) A non-linear response history model for the seismic analysis of high-rise framed buildings. Computers \& Structures, 84, 5, 2004, pp. 318-329. 